Health Team members, not only Board officers.

(c) There must be a clear procedure for closing a home where standards are inadequate. The residents must be protected. One option is for the Health Board to take over the care of the residents in the home.

\section{(7) Continuing education}

There should be continuing education and training of all staff in nursing homes.

Approved by Executive and Finance Committee, March 1991

\title{
The pharmacist's contribution to the management of substance misuse
}

At a recent joint meeting between representatives of the Royal Pharmaceutical Society of Great Britain and the Royal College of Psychiatrists, the contribution of the pharmacist to the management of substance misuse was discussed. It was suggested that each Regional and Local Advisory Committee on substance misuse would benefit from having a community pharmacist member in addition to pharmacists employed by the Health Authorities.

To support this proposal the following points are put forward.

A recent study conducted by Glanz et al (1990) involved a postal survey of a $25 \%$ random sample of community pharmacists in England and Wales. The overall response rate was $79 \%$. The survey indicated that most pharmacists would be prepared to provide equipment to drug injectors and to participate in a local syringe exchange scheme. The survey, having indicated the current involvement of pharmacists, went on to emphasise the potential for building upon that role.

(1) Community pharmacists currently provide dispensing services to most drug addicts

Statistics of Drug Addicts Notified to the Home Office (1989) show that as at December 1988, 12,165 persons were receiving controlled drugs prescribed in treatment for drug addiction.

Of the $25 \%$ random sample of community pharmacies, $23 \%$ of respondents (estimated 2,250 for all pharmacies in England and Wales) were dispensing controlled drugs to persons prescribed these drugs in treatment for drug addiction.

This interaction in itself could provide an opportunity for the provision of information on general healthcare and specific advice on minimising health risks associated with substance misuse.
(2) Community pharmacists can often be the first point of contact for people misusing substances who are not in touch with the substance misuse services

If the local pharmacy is identified as a source of information on substance misuse then the pharmacist's advice might be sought in an informal talk in the first move to tackle a problem by someone reluctant to approach their GP or drug services. The pharmacist is in an ideal position to direct the enquirer to the appropriate expert agency.

(3) Community pharmacists are in a central position to provide advice to the public about substance misuse

Not only advice for the substance misusers but also for anxious parents, spouses, siblings or friends who are concerned about someone close to them whom they believe to be involved in substance misuse.

(4) Community pharmacists are in a central position to provide specific advice to substance misusers about minimising associated health risks

The Glanz survey found that $35 \%$ of pharmacies were asked by at least one drug misuser to sell injecting equipment to them in a four-week period. Thus an estimated 19,647 known or suspected drug misusers would be anticipated to make such a request throughout England and Wales in a four-week period; 676 pharmacists (23\% of respondents) reported that they were currently selling equipment to injecting drug misusers.

(5) Community pharmacists are easily accessible to the public and can provide an appropriate venue for needle exchange schemes

The Monitoring Research Group, Goldsmiths' College Final Report (1988) summarised that syringe exchange schemes have considerable potential to 
help some injecting drug misusers maintain low risk behaviours and to help others adopt them. They also reach injectors who are not in touch with other services.

The Advisory Committee of the Misuse of Drugs (1988) has emphasised the role of the community pharmacy as a point of sale and/or supply of needles and syringes.

(6) Community pharmacists can provide information about trends in misuse of medicinal substances

Pharmacists may well see local trends developing in requests for OTC medicines which could be misused.

Co-operation with their colleagues would at local level lead to them being alerted to be vigilant and to notify the substance misuse services.

\section{References}

Advisory Committee on the Misuse of Drugs (1988).
Glanz, A., Byrne, C. \& Jackson, P. (1990) Prevention of AIDS among Drug Misusers: the role of the high street pharmacy. London: The Institute of Psychiatry.

HOME OFFiCE (1989) Statistics of Drug Addicts Notified to the Home Office, UK, 1988. Area Tables.

MONITORING RESEARCH GROUP (1988) Injecting Equipment Exchange Schemes. Final Report. London: Monitoring Research Group, Goldsmiths' College.

\section{Bibliography}

HoWARTH, W. H. (1986) The pharmacist's role in misuse of medicines. Pharmaceutical Journal, 237, 76-77.

ANON (1988) All pharmacists have a role in drug abuse prevention, says Dr Maddock. Pharmaceutical Journal, 241, 719.

Cherry, P., Tredree, R., Streeter, H. \& Brain, K. (1986) The development of an addiction treatment service. Pharmaceutical Journal, 236, 329-331.

Approved by Council

January 1991.

\section{Special Interest Groups}

In June 1987 Council approved the establishment of 'Special Interest Groups'.

Procedure for establishing a Special Interest Group:

(1) Any Member wishing to establish a Special Interest Group shall write to the Registrar with relevant details.

(2) The Registrar shall forward the application to Council.

(3) If Council approves the principal of establishing such a Special Interest Group then it will direct the Registrar to place a notice in the Bulletin or its equivalent, asking Members of the College to write in support of such a Group and expressing willingness to participate in its activities.

(4) If more than 50 Members reply to this notice, then Council shall formally approve the establishment of the Special Interest Group.
(5) The administrative support provided will be similar to that enjoyed by College Divisions. It should be noted therefore, that the College will maintain the list of members, prepare and distribute notice of meetings but will not provide staff to attend meetings, organise conferences etc.

In accordance with this procedure, Council has approved the establishment of a Management Special Interest Group. Members are invited to write in support of this Group and express willingness to participate in its activities. Members should write to Mrs Jean Wales at the College. If 50 members reply to this notice for the Group, then Council shall formally approve the establishment of this Special Interest Group.

Dr A. GATH Registrar

\section{Career information pack and poster}

The Public Education Committee has recently produced a career information pack and two posters which are available for careers fairs free of charge, and are aimed particularly at medical students thinking of specialising in psychiatry.
The Committee also hopes to produce a short video which should be available later on in the year, on 'A Day in the Life of a Psychiatrist'.

Copies of the posters and the careers packs are available from Deborah Hart at the College upon request. 